\title{
Urological Injuries Due to Gynecological Operations in The Case of Benign Adnexal Lesions and Diseases and Benign Uterine Tumors
}

\author{
Dobrosława L Sikora-Szczęśniak ${ }^{1 *}$ and Szymon Janiszewski ${ }^{2}$ \\ ${ }^{1}$ Department of Gynecology and Obstetrics, Specialist Hospital in Radom, Radom, Poland \\ ${ }^{2}$ The Faculty of Computer Science and Mathematics, Radom, Poland
}

*Corresponding author: Dobrosława L Sikora-Szczęśniak, Gynecology and Obstetrics, Specialist Hospital in Radom, Radom, Poland

\begin{abstract}
ARTICLE INFO
Received: 幽 August 12, 2019

Published: 幽 August 27, 2019

Citation: Dobrosława L SikoraSzczęśniak, Szymon Janiszewski. Urological Injuries Due to Gynecological Operations in The Case of Benign Adnexal Lesions and Diseases and Benign Uterine Tumors. Biomed J Sci \& Tech Res 20(5)2019. BJSTR. MS.ID.003528.
\end{abstract}

Keywords: Gynecological Operations; Urological Injury

\section{ABSTRACT}

Aim: This study was performed to analyze the causes and types of injuries to the urinary organs, secondary to gynecological surgeries. The analysis included surgeries for non-malignant lesions of the adnexa and uterine disorders and non-malignant uterine tumors.

Material and Methods: A retrospective analysis of the medical records of 15 patients with urological injuries and disorders operated on from 1998 to 2017 in the Department of Gynecology and Obstetrics, Specialist Hospital in Radom, Poland.

Results: In the examined group, urinary injuries were noted after hysterectomy (6 cases), uterine body amputation (8 cases), left salpingo-oophorectomy (1 case). There were 2 cases of ureter unilateral injuries and disorders - a total of $4(26.7 \%)$ cases, and 11 $(73.3 \%)$ cases of bladder injury. In 13 cases, these injuries were treated intraoperatively. Reoperation in one of two cases occurred after 2 months due to adhesions of the left ureter with sigmoid, after uterine body amputation with the left ovary, in the other case it was performed on 4th day due to left ureteral severance during laparoscopic left salpingo-oophorectomy. The final surgical outcomes were satisfactory. Urological injuries and disorders secondary to major gynecological surgeries accounted for the majority of urological injuries (14 cases, 93.3\%).

Conclusion: Urological injuries are most common during major gynecological operations. In case of elective major gynecological operations with preoperatively identified risk of urological complications patients should be transferred to reference units where multi-specialist medical care is provided.

\section{Introduction}

Gynecological surgery carries a risk of injury to the urinary structures, especially the ureters and urinary bladder, due to their proximity to the genital organs. The occurrence of these complications is also associated with previous history of abdominal operations and pathological processes such as endometriosis and myomas in the region of the broad uterine ligaments [1]. Moreover, low expertise of a surgeon defined as less than 10 hysterectomies performed per year is enumerated among risk factors for urological injuries [2]. The identification of damage to the urinary organs during surgery allows for immediate repair, reduces the risk of possible complications, and the need for further operations [3]. Injuries to the urinary bladder, depending on the location, are classified as extra- and intraperitoneal [4]. The incidence of this complication during gynecological operations varies and depends on the type of procedure performed. The frequency of urinary bladder injury during open, transvaginal and laparoscopic hysterectomy is $0.9 \%, 0.6 \%$, and $1.0 \%$ respectively [5].

The injuries to the urinary bladder are managed depending on the type and extent of injury. Bladder injuries ranging 2-10 mm can be treated conservatively, maintaining drainage with a Foley 
catheter for 7 days. An incision of 1-2 $\mathrm{cm}$ can be closed with a single layer of slow-absorbing sutures. Incisions longer than $2 \mathrm{~cm}$ are closed with 2-layer continuous slow-absorption sutures. The urothelium should be sutured separately and the submucosal and muscular layers repaired together with another layer of sutures. The stitching tightness can be checked by the bladder irrigation with a solution of methylene blue. Drainage with Foley catheter should be maintained for 7-14 days depending on the damage type $[6,7]$. Vesicovaginal and vesicouterine fistulas are mentioned as main sequalae of the urinary bladder injury. Injury to the urinary bladder during hysterectomy carries a risk of vesicovaginal fistula (VVF), a non-physiological connection between the bladder and the vagina $[5,8]$. This damage can be diagnosed by a Foley catheter in the operating field or urine leak [4]. Gynecological operations occupy the third place on the list of the procedures during which ureteral injuries occur [9]. The ureters are $30-\mathrm{cm}$ long ducts (the left ureter is $2-3 \mathrm{~cm}$ longer), $4-5 \mathrm{~mm}$ in diameter.

They are located retroperitoneally in the abdominal and pelvic cavity. The size, mobility and anatomical location of the ureters make them susceptible to damage [10]. Among iatrogenic ureteral injuries are loss of ureteral continuity (incision, severance) or injuries where the ureteral continuity is maintained, e.g. ligation [9]. The two most susceptible sites of intraoperative injuries are the intersection of the ureter with ovarian vessels at the suspensory ligament and with the uterine artery [1]. The risk of this complication during hysterectomy with salpingo-oophrectomy is estimated at $0.5-2.0 \%$. The risk of ureteral injury is increased, for example, due to massive bleeding requiring management with restricted visibility and the occurrence of, among others, developmental anomalies (accessory ureters, e.g. in the case of duplex kidney, ectopic ureter entering the urinary bladder, ectopic kidney), and the history of previous surgeries or cancer $[3,10,11]$. In the postoperative period, urography (or pyelography) is useful to diagnose ureteral stenoses or obstruction. These examinations can be combined with contrast-enhanced computed tomography or magnetic resonance imaging. Currently, these options are considered standard in the diagnostic work-up of this type of surgical injuries [1]. Some authors argue that contrast-enhanced computed tomography offers higher sensitivity than urography in the diagnosis of ureteral injury, and the latter should be used only if computed tomography is not possible[10].

Ureteral injury with preserved continuity (in the case of ligation or clipping of the ureter) is the simplest to treat. Repair surgery consists in the removal of ligation or clamping from the ureter. In doubtful cases concerning the blood perfusion of the ligated site, the ischemic part of the ureter should be removed and repaired in a manner adjusted for the location of the injury $[9,12]$. Signs of injury to the ureter during or after gynecological surgery require urological consultation and subsequent surgical treatment supervised by a urologist.

\section{Aim of The Study}

The aim of study was to analyze the causes and types of urological injuries, secondary to past gynecological surgeries for non-malignant lesions of the appendages and uterine disorders and non-malignant uterine tumors.

\section{Material and Methods}

The material for retrospective analysis comprised medical records of a 20-year period from 1998 to 2017 from the Department of Gynecology and Obstetrics, Specialist Hospital in Radom, Poland. The analysis found 40 cases of injury to the urinary tract organs sustained during gynecological surgeries. Among them we recorded 15 cases of injured urinary tract structures during and after surgery due to non-malignant lesions of the adnexa, during laparoscopic surgery, and disorders and non-malignant tumors of the uterus. The retrospective analysis of medical records of patients with urinary organs injury considered the following:

Table 1: Non-cancerous lesions in adnexa and diseases and non-malignant tumors in uterus. Type of surgery. Urological diseases and injuries $(\mathrm{N}=15)$.

\begin{tabular}{|c|c|c|c|c|c|c|c|c|c|}
\hline \multicolumn{2}{|c|}{$\begin{array}{l}\text { Type of Surgery During Which } \\
\text { Urological Injury Occurred } \\
\text { Hysterectomy }(\mathrm{N}=6) \text {. Amputation } \\
\text { Of Uterine Body }(\mathrm{N}=8) \text {. }\end{array}$} & \multicolumn{3}{|c|}{$\begin{array}{c}\text { Number of Surgeries and Route of } \\
\text { Operation In Cases of Identified } \\
\text { Disease or Injury }\end{array}$} & \multicolumn{3}{|c|}{$\begin{array}{c}\text { Type of Ureteral Injury Cause of } \\
\text { Disease }(\mathrm{N}=4)\end{array}$} & \multicolumn{2}{|c|}{$\begin{array}{c}\text { Type of Surgery / } \\
\text { Urinary Bladder Injury } \\
\text { (N=11) }\end{array}$} \\
\hline \multirow{2}{*}{\multicolumn{2}{|c|}{ Salpingo-oophorectomy $(\mathrm{N}=1)$. }} & \multirow[t]{2}{*}{ Total } & \multirow[t]{2}{*}{ L-tomy } & \multirow[t]{2}{*}{ L-scopy } & \multirow[t]{2}{*}{$\begin{array}{l}\text { Ureter } \\
\text { severence }\end{array}$} & $\begin{array}{c}\text { Right } \\
\text { ureter } \\
\text { incision. }\end{array}$ & \multirow{2}{*}{$\begin{array}{l}\text { Adhesions } \\
\text { of ureter } \\
\text { (left) and } \\
\text { sigmoid }\end{array}$} & \multirow{2}{*}{$\begin{array}{c}\text { Wall } \\
\text { fragment } \\
\text { removal }\end{array}$} & \multirow[t]{2}{*}{$\begin{array}{l}\text { Wall } \\
\text { transection }\end{array}$} \\
\hline & & & & & & $\begin{array}{c}\text { Stone } \\
\text { removal }\end{array}$ & & & \\
\hline \multirow{2}{*}{$\begin{array}{l}\text { Histerectomy } \\
\text { with salpingo- } \\
\text { oophorectomy }\end{array}$} & bilateral & 4 & $2+2 *$ & $2 *$ & & & & & $4^{*}$ \\
\hline & unilateral & 1 & 1 & & 1 & & & & \\
\hline Hysterectomy & $\begin{array}{l}\text { without } \\
\text { adnexa }\end{array}$ & 1 & 1 & & & & & 1 & \\
\hline \multirow{2}{*}{$\begin{array}{l}\text { Amputation of } \\
\text { uterine body } \\
\text { with salpingo- } \\
\text { oophorectomy }\end{array}$} & bilateral & 1 & 1 & & & & & & 1 \\
\hline & unilateral & 1 & 1 & & & 1 & & & \\
\hline
\end{tabular}




\begin{tabular}{|c|c|c|c|c|c|c|c|c|c|}
\hline \multicolumn{2}{|c|}{$\begin{array}{l}\text { Amputation of uterine body with } \\
\text { salpingoectomy }\end{array}$} & 1 & 1 & & & & & & 1 \\
\hline \multirow{2}{*}{$\begin{array}{l}\text { Amputation of } \\
\text { uterine body }\end{array}$} & $\begin{array}{l}\text { wihtout } \\
\text { adnexa }\end{array}$ & 4 & 4 & & & & & & 4 \\
\hline & $\begin{array}{l}\text { with left } \\
\text { oviduct }\end{array}$ & 1 & 1 & & & & $1^{* *}$ & & \\
\hline \multicolumn{2}{|c|}{$\begin{array}{c}\text { Salpingo-oophorectomy (left) with } \\
\text { salpingeal cyst }\end{array}$} & 1 & 1 & $1^{* * *}$ & $1^{* * *}$ & & & & \\
\hline TOTAL & 15 & 15 & $3 *$ & 2 & 1 & 1 & 1 & 10 & \\
\hline
\end{tabular}

$3^{*}$ - Reoperations after urological injury sustained during laparoscopy

$1^{* *}$ - Reoperation performed after 2 months. Retentio urinae renis sin. Release of ureteral adhesions (left). Catheterisation of ureter from bladder side. Salpingoectomy (left) and salpingo-oophorectomy (right) with ovarian tumor removal. Cystadenoma serosum et cystis corporis lutei.

Removal of uterine cervix.

*** - Reoperation performed on day 4. Nephrostomia interna m. double J.

a) type of surgery, urological defects and disorders (Table 1),

b) histopathological findings and pathological conditions of the genital organs

in the operated women who sustained urological disorders and injuries during surgery (Table 2), c) percentage of lesions and disorders in particular types of surgeries, basic demographic

data, obstetric history (Tables 3-5),

d) risk factors for damage to the ureters and urinary bladder (Table 6).

Table 2: Non-cancerous lesions in adnexa and non-malignant tumors in uterus in women with urological injuries. Histopathological results $(\mathrm{N}=15)$.

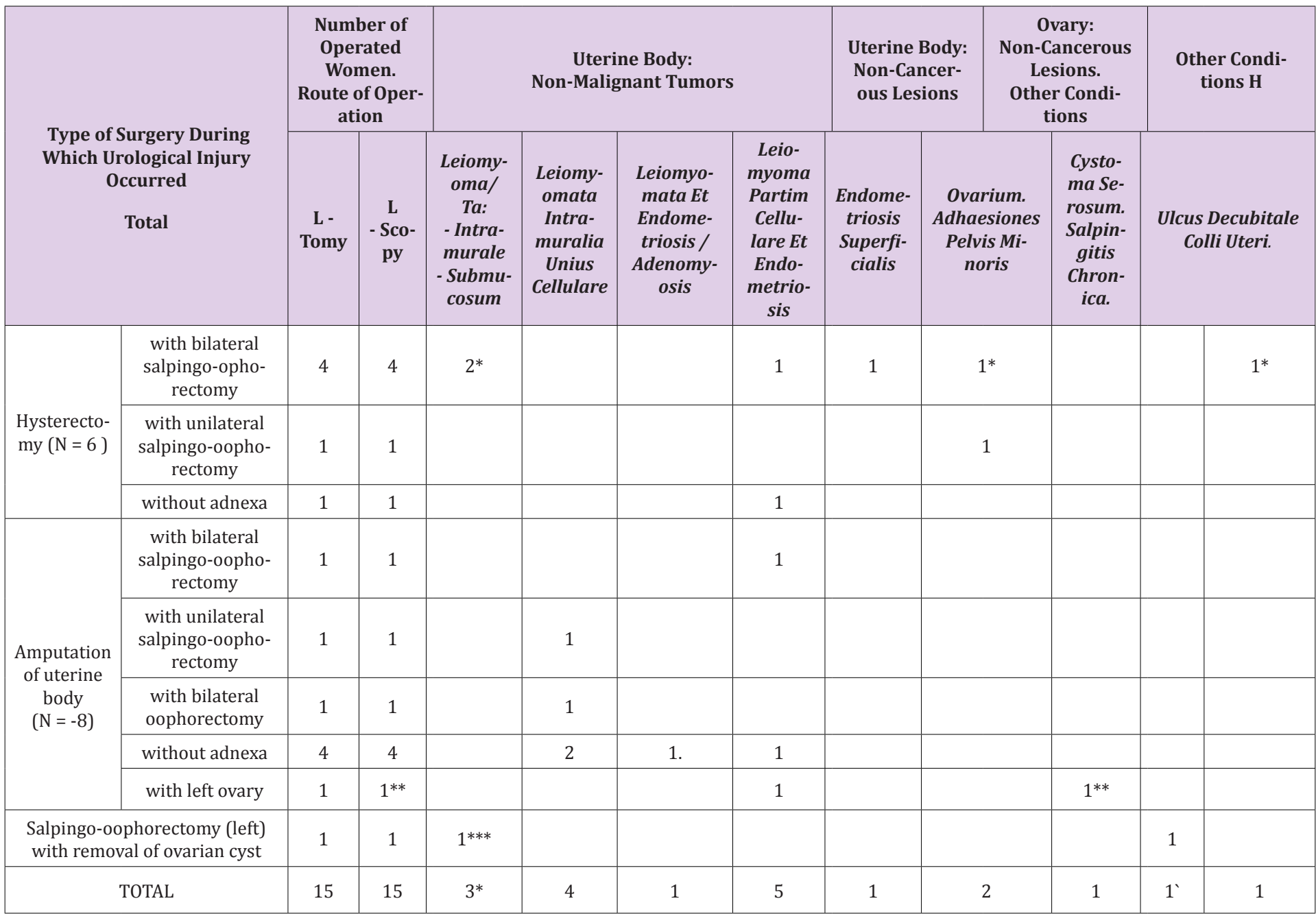


$3^{*}$ - Reoperations after urological injury sustained during laparoscopy

$1^{* *}$ - Reoperation performed after 2 months. Retentio urinae renis sin. Release of ureteral adhesions (left). Catheterisation of ureter

from bladder side. Salpingoectomy (left) and salpingo-oophorectomy (right) with ovarian tumor removal. Cystadenoma serosum et cystis corporis lutei. Removal of uterine cervix.

$1^{* * *}$ - Reoperation performed on day 4 . Nephrostomia interna m. double J.

Table 3: Number and parcentage of patients with urological injuries operated on for non-cancerous adnexal lesions and uterine diseases and and non-malignant tumors $(\mathrm{N}=15)$.

\begin{tabular}{|c|c|c|c|c|c|}
\hline \multirow{2}{*}{$\begin{array}{c}\text { Type of Surgery } \\
\text { Total Number Of Surgeries } \\
\text { (N = 2875) } \\
\text { Number And \% Of Surger- } \\
\text { ies }\end{array}$} & \multirow{2}{*}{$\begin{array}{c}\text { Urological Injuries } \\
\mathrm{N} / \% \\
15(0.522)\end{array}$} & \multicolumn{2}{|c|}{$\begin{array}{l}\text { Ureteral Injuries and Diseases } \\
\text { N / \%. - } 4 \text { (0.139) }\end{array}$} & \multirow{2}{*}{$\begin{array}{c}\text { Urinary Bladder Injury } \\
\text { Sustained During } 2875 \\
\text { Surgeries } \\
\mathrm{N} / \% \\
11(0.382)\end{array}$} & \multirow{2}{*}{$\begin{array}{c}\text { Urinary Bladder Injury } \\
\text { Sustained During Hyster- } \\
\text { ectomy } \\
\text { N / \% }\end{array}$} \\
\hline & & $\begin{array}{c}\text { Ureter Injury } \\
\mathrm{N} / \% \\
2(\mathbf{0 . 0 7 0} \\
\end{array}$ & $\begin{array}{c}\text { Ureter Injury } \\
\quad \mathrm{N} / \% \\
2(0.070)\end{array}$ & & \\
\hline $\begin{array}{l}\text { Total hysterectomy } \\
(\mathrm{N}=653-22.7)\end{array}$ & $6(0.919)$ & $1(0.153)$ & & $5(0.766)$ & \\
\hline $\begin{array}{l}\text { Subtotal hysterectomy } \\
\qquad(\mathrm{N}=1144-39.8)\end{array}$ & $8(0.699)$ & & $\begin{array}{c}2 \\
(0.175)\end{array}$ & $6(0.524)$ & \\
\hline $\begin{array}{l}\text { Total numer of hysterectomies } \\
\qquad(\mathrm{N}=1797-62.5)\end{array}$ & $14(0.779)$ & $1(0.056)$ & $2(0.111)$ & $11(0.612)$ & $\begin{array}{l}12(0.668) \\
2(0.111) \\
\end{array}$ \\
\hline $\begin{array}{l}\text { Laparoscopic adnexectomy } \\
\qquad(\mathrm{N}=1078-37.5)\end{array}$ & $1(0.093)$ & $1(0.093)$ & & & \\
\hline
\end{tabular}

Table 4: Age, body mass, and BMI in patients with urological injuries operated on for non-cancerous adnexal lesions and uterine diseases and non-malignant tumors $(\mathrm{N}=15)$.

\begin{tabular}{|c|c|c|c|c|}
\hline Type of Surgery & Parameter & Mean & Range & SD \\
\hline \multirow{3}{*}{$\begin{array}{c}\text { Hysterectomy with salpingo-oophorectomy: } \\
\text { - bilateral } \\
\text { - unilateral }\end{array}$} & Age & 53.17 & $70-36$ & 9.09 \\
\hline & Body mass & 73 & $90-61$ & 10.84 \\
\hline & BMI & 29.61 & $40.00-24.22$ & 6.46 \\
\hline \multirow{3}{*}{$\begin{array}{c}\text { Amputation of uterine body with salpingo-oophorectomy: } \\
\text { - bilateral and unilateral } \\
\text { - without adnexa } \\
\text { - with salpingectomy/ } \\
\text { oophorectomy }\end{array}$} & Age & 46.63 & $51-43$ & 3.11 \\
\hline & Body mass & 73.5 & $105-54$ & 15.54 \\
\hline & BMI & 27.74 & $36.33-21-63$ & 5.36 \\
\hline \multirow{3}{*}{ Left salpingo-oophorectomy with ovarian cyst removal } & Age & 50 & & \\
\hline & Body mass & 70 & & \\
\hline & BMI & 28.81 & & \\
\hline \multirow{3}{*}{ TOTAL } & Age & 49.47 & $70-43$ & 6.70 \\
\hline & Body mass & 73.07 & $105-54$ & 12.79 \\
\hline & BMI & 28.56 & $40.00-21.63$ & 5.49 \\
\hline
\end{tabular}

Table 5: Number of deliveries in patients with urological injuries and other urological conditions, operated on for adnexal noncancerous lesions and uterine diseases and non-malignant tumors $(\mathrm{N}=15)$.

\begin{tabular}{|c|c|c|c|}
\hline \multirow{2}{*}{ Paremeter } & $\begin{array}{c}\text { Number of Patients Who } \\
\text { Delivered }\end{array}$ & $\begin{array}{c}\text { Number of Deliveries } \\
\text { [Mean/Range] }\end{array}$ & Caesarean section \\
\cline { 2 - 4 } & $\mathbf{1 3} \mathbf{( 8 6 . 7 \% )}$ & 19 & \\
\hline N (\%) of patients who delivered naturally & $8(61.5)$ & 2 & 2 \\
] & $1(7.7)$ & $2.38 / 1-4]$ \\
\hline
\end{tabular}




\begin{tabular}{|c|c|c|c|}
\hline $\mathrm{N}(\%)$ of patients who delivered by CC & $4(30.8)$ & 9 \\
\hline Number of deliveries [total (\%)] & 30 & $19.25 / 1-3]$ & 11 \\
{$[2.2 / 1-3]$} & {$[2.38 / 1-4]$} & {$[1]$} \\
\hline
\end{tabular}

Table 6: Risk factors for ureter and urinary bladder injury in patients operated on for adnexal non-cancerous lesions and uterine diseases and non-malignant tumors $(\mathrm{N}=13$ / 15).

\begin{tabular}{|c|c|c|}
\hline \multicolumn{2}{|c|}{ Risk Factors for Ureter and Urinary Bladder Injury } & $\begin{array}{c}\text { Number of Cases } \\
\text { Total - } 13\end{array}$ \\
\hline \multicolumn{2}{|c|}{ Post-CC condition } & 5 \\
\hline \multicolumn{2}{|c|}{ Past surgeries [apendectomy, umbilical herina] } & $1 \mathrm{Xx}$ \\
\hline \multicolumn{2}{|c|}{ Leiomyoma in vesico-uterine space } & 1 \\
\hline \multicolumn{2}{|c|}{ Ovarian endometrial cysts } & 1 \\
\hline \multicolumn{2}{|c|}{ Adhesion of uterine leiomyoma and urinary bladder wall } & 2 \\
\hline \multirow{3}{*}{$\begin{array}{l}\text { Gynaecological surgeries [N=3] complicated by } \\
\text { urological injuriy }\end{array}$} & $\begin{array}{l}\text { Hysterectomy and Burch procedure; laparoscopy } \\
<1 \text { transverse laparotomy }\end{array}$ & 1 \\
\hline & $\begin{array}{l}\text { Left salpingo-oophorectomy with ovarian cyst } \\
\text { removal. Adhesion with parietal peritoneum } \\
\text { l-scopy < median l-tomy }\end{array}$ & 1 \\
\hline & $\begin{array}{l}\text { Surgery ( laparoscopy performed } 8 \text { yrs ago) for } \\
\text { adnexal endometriosis }\end{array}$ & 1 \\
\hline \multirow{2}{*}{$\begin{array}{c}\text { Urological condition: }[\mathrm{N}=2] \\
\text { - Retentio urinae renis dextri. } \\
\text { - post-amputation of uerine body with left ovary } \\
\text { removal } \\
\text {-Stones in left ureter }\end{array}$} & $\begin{array}{l}\text { Left oophorectomy, right adnexectomy and } \\
\text { uterine cervix removal. Left ureter release from } \\
\text { adhesions. }\end{array}$ & $1 \mathrm{X}$ \\
\hline & $\begin{array}{l}\text { Stone removal from right ureter (uretherotomy); } \\
\text { laparotomy }\end{array}$ & 1 \\
\hline
\end{tabular}

The obtained results were referred to the publications discussing the cases of the urinary organs injured during gynecological operations due to the same type of non-malignant lesions in the adnexa as well as non-malignant disorders and tumors of the uterus.

\section{Results}

Tables 1 and 2 describe the type of ureteral and bladder injuries and histopathological results and pathological lesions in women undergoing surgery for non-malignant disorders of the uterus and appendages and non-malignant uterine tumors. Table 6 lists the hazardous factors likely to affect the course and degree of surgical complexity. In the study group, the operations due to injured urological structures during the treatment of non-malignant disorders and tumors of the genital organs were performed in 15 women, which accounted for $37.5 \%$ of all cases of injuries sustained during gynecological operations.

Injuries of the urinary structures were sustained during:

a. hysterectomy - 6 cases,

b. amputation of the uterine body - 8 cases,

c. left salpingo-oophorectomy due to non-malignant ovarian lesions - 1 case.

The majority of injuries of the urinary structures (14 cases 93.3\%) occurred during major gynecological operations (Tables $1 \& 2$ ). During laparoscopic surgery, there were 3 cases of injured urinary structures, including 2 urinary bladder injuries, and a case of severance of the left ureter. Corrective surgery was performed by laparotomy (Tables $1 \& 2$ ). Among 4 cases of ureteral surgery, there were 2 repair surgeries, and 2 surgeries for disorders impairing ureteral function. They were all unilateral; among them 3 leftsided and 1 right-sided (Table 1). In the group of 15 gynecological operations, ureteral disorders and injuries constituted $26.7 \%$. It is ideal when urological injury is identified during surgery. However, those complications are not always recognized intraoperatively. It is also connected with the coexistence of urological conditions and disorders of the abdominal and pelvic organs.

In one case, the treatment was implemented on the $4^{\text {th }}$ day after surgery. The ureter was severed during laparoscopic removal of the left appendages due to serous cyst of the left ovary and salpingitis. There was one case of blocked urinary outflow from the left kidney due to adhesions located in the ureteral region. This situation occurred 2 months after the amputation of the uterine body with the left ovary (Tables 1 \& 2). The participation of specialist urologists and/or surgeons is often necessary during repair procedures performed for urological injuries sustained during gynecological operations. In the material presented above, specialist urologists participated in all 4 cases of sustained ureteral injuries and conditions impairing ureteral functioning. In one of these operations, a surgeon was also present, and a urologist participated in one surgery of bladder injury repair. Gynecological operations complicated by injured urinary structures carry a risk of greater intraoperative blood loss. Therefore, patients with preoperative risk factors for this type of complications require provision and, if necessary, transfusion of blood and blood products. Transfusions 
of 2 to 5 units of packed red blood cells (PRBCs) in this group of patients were necessary in 6 women (40\%, mean $3.3 \mathrm{U}$ of PRBCs per 1 operated woman).

In $2(13.3 \%)$ cases, where the blood loss during the operation was over 1 liter, it was necessary to transfuse 5 units of PRBCs. The final outcome of treatment of urological disorders and injuries in the study group was satisfactory.

\section{Statistical Analysis}

To compare the frequency of urological injuries and disorders depending on the type of surgery (total hysterectomy, subtotal hysterectomy, and laparoscopic adnexectomy), we formulated a number of hypotheses about the equality of relevant fractions. Individual hypotheses were verified by Student's t test (Table 7A). In total, the difference in the frequency of urological injuries and disorders of the urinary organs between total and subtotal hysterectomy is not statistically significant $(p=0.61)$. Comparison of total hysterectomy with laparoscopic adnexectomy, and subtotal hysterectomy with adnexectomy leads to the rejection of the hypothesis of equal frequency of urological injuries and disorders ( $p$ $=0.008$ and $p=0.012$ respectively). This means that the differences in the frequency of these injuries in the case of total hysterectomy and adnexectomy and subtotal hysterectomy and adnexectomy are statistically significant.

Table 7A: Urological conditions and injuries (total) during total hysterectomy, subtotal hysterectomy, and laparoscopic adnexectomy - $\mathrm{p}$ - values calculated after hypothesis verification about injury ratio equality.

\begin{tabular}{|c|c|c|}
\hline & $\begin{array}{c}\text { Subtotal } \\
\text { Hysterectomy }\end{array}$ & Adnexectomy \\
\hline Total hysterectomy & 0.6107 & 0.008667 \\
\hline Subtotal hysterectomy & - & 0.01223 \\
\hline
\end{tabular}

As for ureteral injuries and disorders, there were no differences in the frequency between particular types of surgery. The following $\mathrm{p}$ values were obtained: total hysterectomy vs. subtotal hysterectomy $\mathrm{p}=0.91$, total hysterectomy vs laparoscopic adnexectomy $\mathrm{p}=0.72$, and subtotal hysterectomy vs laparoscopic adnexectomy $\mathrm{p}=0.60$ (Table 7B). Bladder injuries occurred only in the case of hysterectomy, and with similar frequency after total and subtotal hysterectomy ( $\mathrm{p}=0.53$ ). To sum up, the statistical significance of differences in urological injuries and disorders between hysterectomy and laparoscopic adnexectomy results from non-zero bladder injury rates during hysterectomy (both total and subtotal), and the absence of such injuries during adnexectomy. In addition, we analyzed the age, body mass and BMI of patients who suffered injury to the urinary organs during surgeries for nonmalignant lesions of the genital organs and uterine benign tumors (Table 7C). The mean values of these parameters were determined for particular types of operations, and the hypotheses about their equality were verified using the Student's t test. The comparison found no statistically significant differences between these parameters for total and subtotal hysterectomy (age $p=0.15$, body mass $p=0.94$, BMI $p=0.58$ ). Adnexectomies were excluded from calculations due to the sample size being too small.

Table 7B: Ureteral conditions and injuries during total hysterectomy, subtotal hysterectomy, and laparoscopic adnexectomy - $\mathrm{p}$ - values calculated after hypothesis verification about injury ratio equality.

\begin{tabular}{|c|c|c|}
\hline & $\begin{array}{c}\text { Subtotal } \\
\text { Hysterectomy }\end{array}$ & Adnexectomy \\
\hline Total hysterectomy & 0.9138 & 0.72 \\
\hline Subtotal hysterectomy & - & 0.5985 \\
\hline
\end{tabular}

Table 7c: p- values calculated after hypothesis verification about equality of age, body mass, and BMI in patients undergoing total and subtotal hysterectomy.

\begin{tabular}{|c|c|}
\hline Parameter & $\mathbf{p}$ \\
\hline Age & 0.1519 \\
\hline Body mass & 0.9448 \\
\hline BMI & 0.5788 \\
\hline
\end{tabular}

\section{Discussion}

Urological injury is a complication recorded in app. 1\% of all gynecological surgeries [13]. The rate of ureteral or bladder injury in gynecological surgeries is estimated at $0.5-0.8 \%$ of operated women, the rate increases to over $3 \%$ in the case of hysterectomy with salpingo-oophorectomy. According to Ibeanu et al. the likelihood of urological injury is twice as high in hysterectomy with salpingo-oophorectomy performed due to cervical or endometrial cancer $\geq \mathrm{T} 2$ (II according to the International Federation of Gynecology and Obstetrics, FIGO) [12].

In a publication analyzing 86 cases of urogynecological injuries in a 10-year follow-up period in patients who underwent gynecological surgery in a university hospital, the injures occurred with a total frequency of $0.30 \%$ [14]. Other researchers recorded ureteral and bladder injuries in $4.3 \%$ of all operations among 839 hysterectomies performed due to non-malignant disorders [15].

In the material presented herein, the percentage of injuries to the urinary structures during total and subtotal hysterectomy was $0.92 \%$ and $0.70 \%$ respectively (Table 3 ). Injuries of urinary structures are not always identified intraoperatively. In the presented material, it happened in one case. However, blocked urinary outflow from the left kidney two months after amputation of the uterine body with left ovary is a distant complication, and is a risk factor for this type of postoperative condition (Tables $1 \& 2$ ). In many studies evaluating the frequency of urinary injury during gynecological procedures, ureteral injury was noted in $0.1-2.5 \%$ [16-19]. However, in the analysis of 86 cases of injuries cited above, ureteral damage was reported in $0.083 \%$ [14]. It was close to the recorded rate of $0.093 \%$ injury in the discussed group (Table 3).

Korean authors reported the occurrence of ureteral injury in $1.1 \%$ of women undergoing laparoscopy, and in $1.2 \%$ laparotomies, and a significantly higher rate of ureteral injury in patients with 
risk factors. They concluded that gynecological procedures by laparotomy increase the chances of early detection and intraoperative repair of ureteral injury in patients with risk factors [20]. The use of techniques other than total hysterectomy for the removal of uterus may prevent urological injuries. In 1163 cases of intra-fascial and supra-cervical hysterectomies, ureteral injuries were noted in $0.34 \%$ of operated patients [21]. However, the use of other methods, e.g. laparoscope-assisted vaginal hysterectomy, increase the risk of such injury [22]. In the presented material, among a similar number (1144 cases) of this type of hysterectomy, no case of ureteral damage was noted.

However, there were two cases $(0.17 \%)$ of disorders complicating the functioning of the ureters (Table 3). Ibeanu et al reported less frequent ureteral injury after vaginal hysterectomy compared to laparotomy technique; respectively $0.9 \%$ and $1.7 \%$ [15]. Chłosta et al. stated that the majority of ureteral injuries were left-sided (13/17) and almost all (16/17) occurred after hysterectomy with salpingo-oophorectomy [12]. In the presented group, among injuries requiring ureter repair, three injuries were left-sided and one right-sided. Ureteral injury and two cases of impaired ureteral functioning (a total of 3 cases) occurred during hysterectomy with salpingo-oophorectomy, and in one case during removal of left ovarian tumor (Table 1). Of two cases of ureteral injury, one $(50 \%)$ was identified intraoperatively. In the case of ureter severance during laparoscopic adnexectomy the repair operation was performed on the 4th day. Such postoperative complications occurring after laparoscopy are rarely diagnosed intraoperatively.

The literature review shows that up to $70 \%$ of ureteral injuries remain unrecognized at the time of injury [22]. During open gynecological procedures, the frequency of intraoperative diagnosis of ureteral trauma reaches $30 \%$, while during laparoscopy it is not higher than several per cent [23]. Some authors reported over $60 \%$ rate of intraoperatively identified ureteral injuries [9]. Bladder injury is the most frequent among urinary injuries sustained during gynecological surgeries [1], 5 bladder injuries per 1 ureteral injury are reported. In the studied group, the proportion was 5.5 / 1. On the other hand, along with conditions affecting the functioning of the urinary ways, it was 2.8/1. Bladder injuries (reported in earlier publications) sustained during hysterectomy performed from abdominal and vaginal access were reported in $1.8 \%$ and $0.4 \%$, respectively $[24,25]$. In the publication cited by Moulder et al. analyzing the results of the group of operated Finish women, bladder injury after hysterectomy, uterine body amputation, and vaginal hysterectomy were reported in $0.13 \%, 0.03 \%$ and $0.02 \%$ respectively [26].

In another 10-year study performed in the university hospital, the bladder injury occurred in $0.18 \%$ patients who underwent gynecological operations [14]. Bladder injury was noted in 11 cases which constituted $78.6 \%$ of urological injuries among 1797 hysterectomies performed by abdominal and vaginal route, and by laparoscopy. In contrast we recorded $73.3 \%$ of 2875 operations in the study group. Among 1078 laparoscopies due to nonmalignant conditions in the appendages no bladder injury was noted. The identification of risk factors for ureteral and bladder injury is important in the prevention of these complications. Those may complicate the course of surgery and increase the risk of urinary organ injury. If the risk identification is possible, then it is also possible to perform additional investigations or change the protocol of surgery to reduce the risk. However, in $50 \%$ of patient's preoperative identification of ureteral damage was unsuccessful [27]. In the study group, they were noted in 13 (86.7\%) patients (Table 6). Another complication is the loss of blood during the procedure. Blood loss during surgery over 1 liter is a documented risk factor for bladder and ureter injury $[5,8]$. Such situation occurred twice in the study group.

Measures preventing urological injury include voiding the urinary bladder prior to laparotomy or laparoscopy, which reduces the likelihood of its injury during the procedure. Dissection of the bladder from the lower segment of the uterus should always be carried out sharply to protect part of its wall located over the trigone. The visualization or palpation of the ureter by the surgeon gynecologist is crucial in preventing its damage [27]. A careful surgical technique with the identification of the pelvic structures is probably the best method to prevent ureteral injury [28,29]. In order to minimize the risk of late sequelae of such injuries, the likelihood of their occurrence should always be considered and immediate action taken to recognize them. The latest study results justify and support the usefulness of routine cystoscopy in such cases, especially after hysterectomy, anterior vaginoplasty and other gynecological procedures hazardous for the lower segment of the urinary tract $[15,29]$.

\section{Conclusion}

Urological injuries are most frequently sustained during major gynecological surgeries. Operations caring the risk of urological complications should be performed by experienced surgeons who have good knowledge of surgical anatomy and skills to deal with complications during operation. Patients at risk of urological complications detected preoperatively, particularly those qualified for elective major gynecological operations, should be referred to a reference center to be provided with multidisciplinary medical care.

\section{References}

1. Sharp HT, Adelman MR (2016) Prevention, recognition, and management of urologic injuries during gynaecologic surgery. Obstetrics \&Gynecology 127(6): 1085-1096.

2. Sandberg EM, Cohen SL, Hurwitz S, Einarsson JI (2012) Utility of cystoscopy during hysterectomy. Obstet. Gynecol 120(6): 1363-1370.

3. Iglesia C, Edwards SR (1999) Intraoperative assessment and treatment of ureteral damage. Ginekologia po Dyplomie 1: 71-75.

4. Jóźwik M, Jóźwik M, Jóźwik M (2008) Maternal complications associated with Caesarean section. Perinat Neonati Gin 1 (1): 57-65. 
5. Duong TH, Gellasch TL, Adam RA (2009) Risk factors for the development of vesicovaginal fistula after incidental cystotomy at the time of a benign hysterectomy. Am J ObstetGynecol 201(5): 512: e1-e4.

6. Hema KR, Johanson R (2001) Techniques for performing caesarean section. Best Pract Res Clin Obstet Gynaecol 15(1): 17-47.

7. Cordon BH, Fracchia JA, Armenakas NA (2014) Iatrogenic non endoscopic bladder injuries over 24 years: 127 cases at a single institution. Urology 84(1): 222-226.

8. Duong TH, Taylor DP, Meeks GR (2011) A multicenter study of vesicovaginal fistula following incidental cystotomy during benign hysterectomies. Int Urogynecol J 22(8): 975-979.

9. Cichoń W, Maciukiewicz P (2014) Iatrogenic ureteral injuries in adults diagnosis and treatment. Przegl Lek 71(12): 700-702.

10. Bużański T (2014) Urinary tract injuries. Post Nauk Med Suppl 1: 46-50.

11. Burks FN, Santucci RA (2014) Management of iatrogenic ureteral injury. Ther Adv Urol 6(3): 115-124.

12. Chłosta P, Antoniewicz AA, Otlewski P, Pinkas E (2000) Iatrogenic lesions of the lower ureters and bladder in women after gynecological and obstetric surgery. Nowa Med 5.

13. Gilmour DT, Baskett TF (2005) Disability and litigation from urinary tract injuries at benign gynaecologic surgery in Canada. ObstetGynecol 105(1): 109-114.

14. Satitriniramal S, Manonai J (2017) Urologic injures during gynecologic surgery, a 10-year review. J Obstet Gynaecol Res 43 (3): 557-563.

15. Ibeanu OA, Chesson RR, Echols KT, Nieves M, Busangu F, et al. (2009) Urinary tract injury during hysterectomy based on universal cystoscopy. Obstet Gynecol 113(1): 6-10

16. Koukouras D, Petsas T, Liatsikos E, Kallidonis P, Sdralis EK, et al. (2010) Percutaneous minimally invasive management of iatrogenic ureteral injuries. J Endourol 24(12): 1921-1927.

17. Liatsikos EN, Karnabatidis D, Katsanos K, Kraniotis P (2006) Uretera injuries during gynaecologic surgery: treatment with a minimally invasive approach. J Endourol 20(12): 1062-1067.

\section{ISSN: 2574-1241}

DOI: 10.26717/BJSTR.2019.20.003528

Dobrosława L Sikora-Szczęśniak. Biomed J Sci \& Tech Res

This work is licensed under Creative Commons Attribution 4.0 License

Submission Link: https://biomedres.us/submit-manuscript.php
18. Dorairajan G, Rani PR, Habeebullah S, Dorairajan LN (2004) Urological injuries during hysterectomies: a 6-year review. J Obstet Gynaecol Res 30(6): 430-435

19. Yossepowitch O, Baniel J, Livne PM (2004) Urological injuries during caesarean section: intraoperative diagnosis and management. J Urol 2004 172(1): 196-199.

20. Park JH, Park JW, Song K, Moon KJ (2012) Ureteral injury in gynaecologic surgery: a 5-year review in a community hospital. Korean J Urol 53(2): 120-125.

21.Jung SK, Huh CY (2008) Ureteral injuries during classic intrafascial supracervical hysterectomy: an 11-year experience in 1163 patients. J Minim Invasive Gynecol 15(4): 440-445.

22. Ostrzeński A, Radolinski B, Ostrzenska KM (2003) A review of laparoscopic ureteral injury in pelvic surgery. Obstet Gynecol Surv 58(12): 794-799.

23. Mahendran HA, Praveen S, Ho C, Goh EH, Tan GH, et al. (2012) Iatrogenic ureter injuries: eleven years' experience in a tertiary hospital. Med J Malaysia 67(2): 169-172.

24. Phipps MG, Watabe B, Clemons JL, Weitzen S, Myers DL (2005) Risk factors for bladder injury during cesarean delivery. Obstet Gynecol 105(1): 156-160.

25. Aronson MP, Bose TM (2002) Urinary tract injury in pelvic surgery. Clin Obstet Gynecol. 45(2): 428-438.

26. Moulder JK, Cohen SL (2013) Prevention of urinary tract damage during hysterectomy. Four strategies for success. Ginekol Dypl 15(2): 13-22.

27. Chan JK, Morrow J, Manetta A (2003) Prevention of ureteral injuries in gynecologic surgery. Am J Obstet Gynecol 188(5): 1273-1277.

28. Hardy Fairbanks A, Strohbehn K, Aronson MP (2010) Prevention and diagnosis of damage to the urinary tract during pelvic surgery. Ginekol Dypl 12 (6): 68-74.

29. Brubaker L (2009) Is routine cystoscopy an essential? intraoperative test at hysterectomy. Obstet Gynecol 113(1): 2-3.

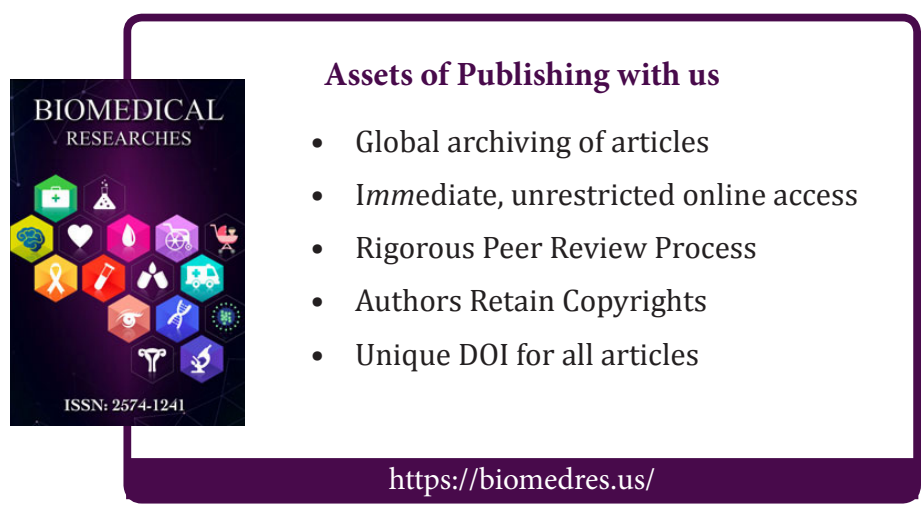

